\title{
Photooxidation of Some Organic Sulfides under UV Light Irradiation Using Titanium Dioxide Photocatalyst
}

\author{
Hakimeh Vosooghian and Mohammad Hossein Habibi \\ Department of Chemistry, University of Isfahan, Isfahan 81746-73441, Iran \\ Received 7 April 2006; Revised 4 October 2006; Accepted 9 October 2006 \\ Recommended by Terry Egerton
}

The photocatalytic oxidation of three organic sulfide compounds (thioethers); methyl phenyl sulfide (MPS), benzyl phenyl sulfide (BPS), and diphenyl sulfide (dPS) using titanium dioxide $\left(\mathrm{TiO}_{2}\right)$ photocatalyst suspension under UV light irradiation in aqueousacetonitrilic (5/95), was studied. Three types of experiments were carried out: (a) the solution was eliminated from atmospheric oxygen by a flow of argon before irradiation, (b) the solution was irradiated with continuous bubbling of oxygen, and (c) the irradiation was carried out at neutral atmospheric oxygen conditions. Results showed that the process will proceed in the presence of pure oxygen much better than atmospheric oxygen or in the absence of oxygen. In fact, no detectable products were observed in the presence of atmospheric oxygen or argon flux. Besides the main products such as methyl phenyl sulfoxide, benzyl phenyl sulfoxide, diphenyl sulfoxide, diphenyl disulfide, benzaldehyde, phenyl propyl sulfide, and n-buthyl phenyl sulfide, trace concentrations of dibenzyl, biphenyl, thiophenol, benzyl alcohol, benzene, benzyl phenyl sulfone, diphenyl sulfone, and methyl phenyl sulfone were detected. Thus in summary, this study provides an example of specific, controlled oxidative chemistry in organic substrates adsorbed on photoactivated $\mathrm{TiO}_{2}$ surface.

Copyright (c) 2007 H. Vosooghian and M. H. Habibi. This is an open access article distributed under the Creative Commons Attribution License, which permits unrestricted use, distribution, and reproduction in any medium, provided the original work is properly cited.

\section{INTRODUCTION}

Reduced sulfur compounds such as sulfides, disulfides, and mercaptans are the by-products of industrial processes and are known as waste, natural waters, and the earth's atmosphere pollutants $[1,2]$. The spontaneous oxidation of these sulfides leads to formation of tropospheric $\mathrm{SO}_{2}$, which is eventually converted into $\mathrm{H}_{2} \mathrm{SO}_{4}$, one of the main components in acidic rains through the reaction with atmosphere humidity [3]. Since the smells of these organic sulfides are often unpleasant for human life, their odor treatment is important.

The photooxidation of sulfur containing compounds in the presence of singlet oxygen has been investigated in the last decades and several of mechanisms have been identified, depending on the reaction conditions.

Titanium dioxide $\left(\mathrm{TiO}_{2}\right)$ has been vigorously used as the photocatalyst for environmental clean up [4-11] and it has been utilized for technological applications $[12,13]$, because of distinguished characteristics [14, 15]: (a) it is inexpensive, nontoxic, and very stable with high photocatalytic efficiency, (b) it promotes ambient temperature oxidation of the major classes of indoor air pollutants, (c) complete degradation of a broad range of pollutants can be achieved under certain operating conditions, and (d) no chemical additives are required. It is well known that electron-hole pairs are generated when $\mathrm{TiO}_{2}$ is irradiated by UV photons with energy higher than the $\mathrm{TiO}_{2}$ band gap energy $(3.2 \mathrm{eV})$ and these charge carriers can migrate to the $\mathrm{TiO}_{2}$ surface to initiate redox reactions with adsorbated substrates. However, the mechanism of photooxidation of sulfides on the $\mathrm{TiO}_{2}$ surface is still under discussion [16-23], it is proposed that the surface hydroxyl groups react with the holes to form the surface-bound $\mathrm{OH}$ radicals, which then oxidize the surface absorbed substrates. The chemical identification of the hydroxylated oxidation intermediate, EPR detection of surface hydroxyl radicals in aqueous $\mathrm{TiO}_{2}$ sols, the scavengering hydroxyl radicals, and the kinetic isotope effects support this mechanism [24-32]. Several researchers also have reported that the surface bound $\mathrm{OH}$ radicals are key species for oxidation reaction because the diffusion of surface-bound $\mathrm{OH}$ radicals from the $\mathrm{TiO}_{2}$ surface into the bulk solution is minimal $[32,33]$. The effectiveness of large particles in these reactions is understandable from the properties of 
$\mathrm{TiO}_{2}$ particles, which indicate that band bending is necessary to oxidize sulfide compounds. To develop the band bending in particles, their size and donor density are important. Usually, rutile powders have larger particle sizes than the anatase powders, because they are produced at higher temperature, and thus are advantageous for band bending [34].

Recently, Majima et al. have reported the one-electron oxidation of several aromatic compounds adsorbed on the surface of the $\mathrm{TiO}_{2}$ powder suspension in $\mathrm{CH}_{3} \mathrm{CN}$ by nanosecond time-resolved diffuse reflectance (TDR) spectroscopy and they have concluded that the $\mathrm{OH}$ groups play an important role in the adsorption on the surface of $\mathrm{TiO}_{2}$ and the efficiency of the one-electron oxidation of the substrates [23, 35-37].

In a nonaqueous medium or in the atmosphere especially, it is expected that the $\mathrm{TiO}_{2}$ particle surfaces are the main reaction fields for the direct oxidation of adsorbated substrate. However, only a few quantitative studies have been reported on the oxidation processes of organic compounds on the $\mathrm{TiO}_{2}$ particle surfaces and the interaction between the substrate and $\mathrm{TiO}_{2}$ surface. Fox and Coworkers notified that many oxidation reactions appear to occur due to direct electron transfer from several substrates to the photoexcited $\mathrm{TiO}_{2}$ particles in a nonaqueous solution such as acetonitrile [20, 38, 39].

Vorontsov et al. have researched the photocatalytic gasphase oxidation of diethyl sulfide over several types of $\mathrm{TiO}_{2}$ photocatalysts. Several organic products were detected in the gas phase and on the catalytic surface corresponding to C$\mathrm{S}$ bond cleavage and direct oxidation of sulfur or carbon atoms. Carbonate and sulfate species, detected on the $\mathrm{TiO}_{2}$ surface after complete photooxidation of diethyl sulfide, are suggested as being responsible for $\mathrm{TiO}_{2}$ deactivation. Organic radical cations are one of the most important intermediates in the photochemical electron-transfer reactions $[40,41]$.

Recently, we have reported the heterogeneous photocatalytic mineralization of some thiols on the Degussa P25 TiO 2 $[42,43]$, some cyclic saturated amines on the ZnO Photocatalyst [44] and some organic sulfides using aqueous suspension of titanium dioxide suspension [34]. But to the best of our knowledge from literature, less attention has been paid to the quantitative studies on the photocatalytic oxidation processes of the organic sulfides and their mechanism in a nonaqueous medium. Therefore, in the present paper we have investigated the one-electron oxidation processes of methyl phenyl sulfide (MPS), benzyl phenyl sulfide (BPS) and diphenyl sulfide (dPS) adsorbed on the surface of $\mathrm{TiO}_{2}$ powder in organic suspension. We observed a wide range of oxidation products using gas chromatography-mass spectroscopy (GC-MS) analytical procedures, during photocatalytic oxidation of the $\mathrm{TiO}_{2}$ powder suspended in organic medium. We chose acetonitrile as the solvent for the photocatalytic reactions since this solvent is relatively stable and gives results for comparison. Furthermore, addition of oxygen was examined in order to increase the rate of oxidation reaction and variety of products. The results obtained here can be used as the reference for evaluating reactions in hydrocarbons, which aim at the development of the photooxidative desulfuruzation process.

\section{EXPERIMENTS}

\subsection{Materials}

Titanium dioxide powder $\left(\mathrm{TiO}_{2}\right)$ used as photocatalyst was commercially available and supplied from Aldrich. These particles were composed mostly of rutile and had a BET surface area of $22 \mathrm{~m}^{2} \mathrm{~g}^{-1}$. Methyl phenyl sulfide (MPS), benzyl phenyl sulfide (BPS), diphenyl sulfide (dPS), and accetonitril (analytical grade) were prepared from Merck and used without further purification. The structure of the initial organic sulfides is summarized in Scheme 1.

\subsection{Photooxidation equipment}

The oxidation processes were carried out in the Pyrex tubular photoreactor using a $400 \mathrm{~W}$ high pressure mercury lamp as a light source. The suspension inside the photoreactor was continuously agitated by a magnetic stirrer. A constant temperature water bath was connected to the reactor and thermostat (Hake model F-122) was set to $25-30^{\circ} \mathrm{C}$. Oxygen or argon was introduced to the solution from gas cylin-

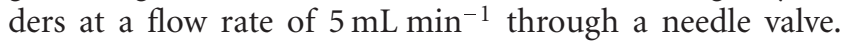
The set up used in this study has been described previously [34].

\subsection{Photoirradiation procedure and analyses}

In each experiment $20 \mathrm{~mL}$ of MPS, MBS or dPS aqueousacetonitrilic $(5 / 95)$ solution $\left(5 \times 10^{-2} \mathrm{M}\right)$ was placed in a photoreactor and $50 \mathrm{mg}$ of $\mathrm{TiO}_{2}$ photocatalyst was added to the solution.

Three types of experiments were carried out: (a) the solution was eliminated from atmospheric oxygen by a flow of argon before irradiation, (b) the solution was irradiated with continuous bubbling of oxygen, and (c) the irradiation was carried out at neutral atmospheric oxygen conditions.

After illumination time at constant temperature (25$30^{\circ} \mathrm{C}$ ), photocatalysts were completely removed by a Hettich EBA 85 centrifuge. Then solutions were filtered through a Millipore filter (pore size $0.22 \mu \mathrm{m}$ ). The organic products were separated and determined by an analytical gas chromatographic instrument using a Fisons 8060 series gas chromatograph equipped with a flame ionization detector and OV-1 $15 \mathrm{~m} \times 0.32 \mathrm{~mm}$ column. The GC-MS analysis was carried out utilizing a Fisons 8060 GC and a Trio 1000 mass selective detector. Some of the products were separated by a thin-layer chromatography (TLC) using $\mathrm{CCl}_{4}: \mathrm{CH}_{3} \mathrm{OH}$, $15: 1$ as solvent and were recrystallized using methanol. The ${ }^{1} \mathrm{H}$ NMR spectera of these compounds were obtained mostly from acetone- $\mathrm{d}_{6}$ solutions with a Bruker Advance RDX $500 \mathrm{MHz}$ spectrometer. IR spectroscopy (Philips, PU 9716) was employed as an additional tool for characterization of some final reaction products. 


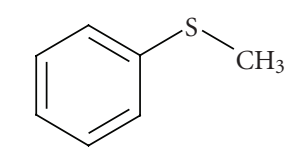

Methyl phenyl sulfide (MPS)

(a) Methyl phenyl sulfide (MPS)

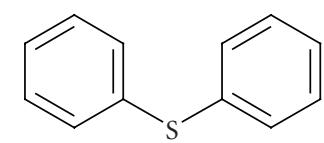

Diphenyl sulfide (dPS)

(b) Diphenyl sulfide (dPS)

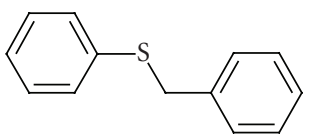

Benzyl phenyl sulfide (BPS)

(c) Benzyl phenyl sulfide (BPS)

Scheme 1: Molecular structure of the initial organic sulfides and their symbols.

\section{RESULTS AND DISCUSSION}

\subsection{Photooxidation products and their chemical yields}

The heterogeneous photooxidation of MPS, BPS, and dPS has been examined. The list of all products detected after photocatalytic oxidation is given in Table 1. Besides of the main products such as methyl phenyl sulfoxide, benzyl phenyl sulfoxide, diphenyl sulfoxide, diphenyl disulfide, benzaldehyde, phenyl propyl sulfide, and n-buthyl phenyl sulfide, trace concentrations of dibenzyl, biphenyl, thiophenol, benzyl alcohol, benzene, benzyl phenyl sulfone, diphenyl sulfone, and methyl phenyl sulfone were detected. Experiments with a controlled flux of oxygen and argon were monitored. The obtained results were compared with the results of photocatalytic oxidation in the neutral atmosphere. We observed that the process will proceed in the presence of pure oxygen much better than atmospheric oxygen or in the absence of oxygen. In fact, no detectable products were observed in the presence of atmospheric oxygen or argon flux. In addition, the effect of $\mathrm{TiO}_{2}$ photocatalyst on the yield of products was investigated. As a result, to obtain an efficient photooxidation reaction, presence of $\mathrm{TiO}_{2}$ was necessary and lack of photocatalyst leads to the sharp reduction of photooxidation products. In fact, no products were detected during photooxidation processes in the absence of $\mathrm{TiO}_{2}$ photocatalyst.

\subsection{Mechanism of products formation over $\mathrm{TiO}_{2}$}

One may speculate on possible mechanisms lying behind the formation of detected products. Generally, the following sequence of events is thought to be responsible for photocatalytic activity of $\mathrm{TiO}_{2}$ particles. It is well known that $\mathrm{TiO}_{2}$ particles generate free charge carriers, electrons and holes, under the bounding gap excitation (1),

$$
\mathrm{TiO}_{2} \stackrel{\mathrm{h} v}{\longrightarrow} \mathrm{h}_{\mathrm{VB}}^{+}+\mathrm{e}_{\mathrm{CB}}^{-} .
$$

After their generation within the short light pulse, both electron and hole are extremely rapidly trapped in surface states of the semiconductor particle within subpicoseconds or a few picoseconds after excitation [5] (2):

$$
\begin{gathered}
\mathrm{h}_{\mathrm{VB}}^{+} \longrightarrow \mathrm{h}_{\mathrm{tr}}^{+}, \\
\mathrm{e}_{\mathrm{CB}}^{-} \longrightarrow \mathrm{e}_{\mathrm{tr}}^{-} .
\end{gathered}
$$

According to previous research activities, these photogenerated carriers then react with variously dissolved or absorbed component. The captured positive hole oxidizes organic molecules by surface hydroxyl radicals. The fast recombination kinetics of the untrapped or trapped charge carriers have been studied in detail by several groups [45-49]. Although most trapped charge carriers recombine quickly, that is, within less than 30 ps (3):

$$
\mathrm{e}_{\mathrm{tr}}^{-}+\mathrm{h}_{\mathrm{VB}}^{+}\left(\mathrm{h}_{\mathrm{tr}}^{+}\right) \longrightarrow \text { heat. }
$$

The sequence of the processes can include water dissociation on the $\mathrm{TiO}_{2}$ surface due to formation of surface hydroxyl group:

$$
\mathrm{H}_{2} \mathrm{O} \stackrel{\mathrm{TiO}_{2}}{\longrightarrow} \mathrm{H}^{+}+\mathrm{OH}^{-} \text {. }
$$

Followed by oxidation of hydroxide group by the hole:

$$
\mathrm{OH}^{-}+\mathrm{h}_{\mathrm{VB}}^{+}\left(\mathrm{h}_{\mathrm{tr}}^{+}\right) \longrightarrow \mathrm{HO}^{\bullet}
$$

In the oxidation of organic compounds, the hydroxyl radical $\left(\mathrm{HO}^{\bullet}\right)$, which comes from the oxidation of adsorbed water or $\mathrm{OH}^{-}$, is the primary oxidant. The captured electrons reduce added dioxygen to the superoxide radical anions, where the presences of oxygen can prevent the recombination of holeelectron pairs,

$$
\begin{gathered}
\mathrm{O}_{2}+\mathrm{e}^{-} \longrightarrow \mathrm{O}_{2}^{-} \\
\mathrm{OH}^{-}+\mathrm{h}^{+} \longrightarrow \mathrm{HO}^{\bullet}
\end{gathered}
$$

On the basis of various photooxidation products of the consideration thioethers, several pathways are possible to discuss the mechanism of these reactions.

The adsorbed thioethers on the $\mathrm{TiO}_{2}$ surface can oxidize by trapped positive holes to produce sulfide radical cations. The formation of sulfur radical cation as intermediate in the photosensitized oxidation of sulfides in reality is accepted and proved. The redox potential of sulfides is about $+1.8 \mathrm{~V}$ with respect to the normal hydrogen electrode that is lower than redox potential of holes in $\mathrm{TiO}_{2}(+3 \mathrm{~V})[40]$ so that the formation of sulfide radical cation by hole is clear:

$$
\mathrm{C}_{6} \mathrm{H}_{5} \mathrm{SCH}_{2} \mathrm{C}_{6} \mathrm{H}_{5}+\mathrm{h}_{\mathrm{VB}}^{+}\left(\mathrm{h}_{\mathrm{tr}}^{+}\right) \longrightarrow \mathrm{C}_{6} \mathrm{H}_{5} \mathrm{~S}^{\bullet+} \mathrm{CH}_{2} \mathrm{C}_{6} \mathrm{H}_{5} \text {. }
$$

The hydrolysis of this radical cation must take place:

$\mathrm{C}_{6} \mathrm{H}_{5} \mathrm{~S}^{\bullet+} \mathrm{CH}_{2} \mathrm{C}_{6} \mathrm{H}_{5}+\mathrm{H}_{2} \mathrm{O} \longrightarrow \mathrm{C}_{6} \mathrm{H}_{5} \mathrm{~S}^{\bullet}+\mathrm{C}_{6} \mathrm{H}_{5} \mathrm{CH}_{2} \mathrm{OH}+\mathrm{H}^{+}$.

Further oxidation of the $\mathrm{C}_{6} \mathrm{H}_{5} \mathrm{CH}_{2} \mathrm{OH}$ intermediate on the $\mathrm{TiO}_{2}$ surface led to the formation of benzaldehyde:

$$
\mathrm{C}_{6} \mathrm{H}_{5} \mathrm{CH}_{2} \mathrm{OH} \underset{\mathrm{h} v}{\stackrel{\mathrm{TiO}_{2}}{\longrightarrow}} \mathrm{C}_{6} \mathrm{H}_{5} \mathrm{CHO} .
$$


TABLE 1: List of the observed oxidation products and their percentages during photocatalytic oxidation of 20 mL aqueous-acetonitrilic (5/95) solution of MPS, BPS or dPS $\left(5 \times 10^{-2} \mathrm{M}\right)$ over $\mathrm{TiO}_{2}$ using $400 \mathrm{~W}$ high pressure mercury lamp at $25-30^{\circ} \mathrm{C}$ after $24 \mathrm{~h}$ irradiation time; and flux of $\mathrm{O}_{2}\left(5 \mathrm{~mL} \mathrm{~min}^{-1}\right)$.

\begin{tabular}{|c|c|c|c|c|c|c|}
\hline \multirow{2}{*}{ No } & \multirow{2}{*}{ Chemical name } & \multirow{2}{*}{ Structural formula } & \multirow{2}{*}{$\begin{array}{l}\text { Identification } \\
\text { based on }\end{array}$} & \multicolumn{3}{|c|}{$\begin{array}{l}\text { aYields base on } \\
\text { initial sulfides }\end{array}$} \\
\hline & & & & MPS & BPS & dPS \\
\hline 1 & Thiophenol & & ${ }^{\mathrm{b}} \mathrm{MS}$ & & Trace & Trace \\
\hline 2 & $\begin{array}{l}\text { Methyl phenyl } \\
\text { sulfoxide }\end{array}$ & & $\begin{array}{c}\mathrm{MS},{ }^{1} \mathrm{H} \text { NMR, } \\
{ }^{\mathrm{c}} \mathrm{IR}\end{array}$ & 54 & & \\
\hline 3 & $\begin{array}{l}\text { Bezyl phenyl } \\
\text { sulfoxide }\end{array}$ & & $\begin{array}{c}\text { MS, }{ }^{1} \mathrm{H} \text { NMR, } \\
\text { IR }\end{array}$ & & 50 & \\
\hline 4 & $\begin{array}{l}\text { Diphenyl } \\
\text { sulfoxide }\end{array}$ & & $\begin{array}{c}\text { MS, }{ }^{1} \mathrm{H} \text { NMR, } \\
\text { IR }\end{array}$ & & & 72 \\
\hline 5 & $\begin{array}{l}\text { Diphenyl } \\
\text { disulfide }\end{array}$ & & MS & $\sim 4$ & $\sim 4$ & $\sim 5$ \\
\hline 6 & Benzaldehyde & & MS & & 5 & \\
\hline 7 & $\begin{array}{l}\text { Phenyl propyl } \\
\text { sulfide }\end{array}$ & & MS & Trace & 5 & 3 \\
\hline 8 & $\begin{array}{l}\text { n-buthyl phenyl } \\
\text { sulfide }\end{array}$ & & MS & Trace & 5 & 8 \\
\hline 9 & Biphenyl & & MS & & Trace & \\
\hline 10 & Benzyl alcohol & & MS & & Trace & \\
\hline 11 & Benzene & & MS & Trace & Trace & Trace \\
\hline 12 & Dibenzyl & & MS & & Trace & \\
\hline 13 & $\begin{array}{l}\text { Benzyl phenyl } \\
\text { sulfone }\end{array}$ & & MS & & & Trace \\
\hline 14 & $\begin{array}{l}\text { Diphenyl } \\
\text { sulfone }\end{array}$ & & MS & & Trace & \\
\hline 15 & $\begin{array}{l}\text { Methyl phenyl } \\
\text { sulfone }\end{array}$ & & MS & Trace & & \\
\hline
\end{tabular}

${ }^{a}$ Only yield of each product is given under initial sulfides

${ }^{b}$ Mass spectrum;

${ }^{\mathrm{c}}$ Infera red spectrum 
Dimerization of two thiyl radicals caused the formation of disulfides (diphenyl disulfide), which was observed in the experiment in trace value,

$$
\mathrm{C}_{6} \mathrm{H}_{5} \mathrm{~S}^{\bullet}+\mathrm{C}_{6} \mathrm{H}_{5} \mathrm{~S}^{\bullet} \longrightarrow \mathrm{C}_{6} \mathrm{H}_{5} \mathrm{SSC}_{6} \mathrm{H}_{5} \text {. }
$$

It is possible to describe the formation of thiyl radicals and benzaldehyde in another way. As was observed by pulse radiolysis, hydroxyl radical react with thioether and adduct $\left(\mathrm{RR}^{\prime} \mathrm{S}^{\bullet}-\mathrm{OH}\right)$ can be formed, which at low concentration of thioether leaving out of $\mathrm{H}_{2} \mathrm{O}$ lead to formation the $\mathrm{RSR}^{\prime}$ $(-\mathrm{H})^{\bullet}$ radical. The next possible steps can include protonation followed by attack by a surface hydroxide group due to formation of thioether $\alpha$-carbon radical:

$$
\begin{gathered}
\mathrm{C}_{6} \mathrm{H}_{5} \mathrm{SCH}_{2} \mathrm{C}_{6} \mathrm{H}_{5} \stackrel{+\mathrm{HO}^{\bullet}}{\rightarrow} \mathrm{C}_{6} \mathrm{H}_{5} \mathrm{SC}^{\bullet} \mathrm{HC}_{6} \mathrm{H}_{5}, \\
\mathrm{C}_{6} \mathrm{H}_{5} \mathrm{SC}^{\bullet} \mathrm{HC}_{6} \mathrm{H}_{5}+\mathrm{H}^{+} \longrightarrow \mathrm{C}_{6} \mathrm{H}_{5} \mathrm{SC}^{\bullet+} \mathrm{H}_{2} \mathrm{C}_{6} \mathrm{H}_{5}, \\
\mathrm{C}_{6} \mathrm{H}_{5} \mathrm{SC}^{\bullet+} \mathrm{H}_{2} \mathrm{C}_{6} \mathrm{H}_{5}+\mathrm{OH}^{-} \longrightarrow \mathrm{C}_{6} \mathrm{H}_{5} \mathrm{~S}^{\bullet}+\mathrm{C}_{6} \mathrm{H}_{5} \mathrm{CH}_{2} \mathrm{OH} .
\end{gathered}
$$

As it was mentioned above, further oxidation of $\mathrm{C}_{6} \mathrm{H}_{5}$ $\mathrm{CH}_{2} \mathrm{OH}$ leads to the formation of benzaldehyde and dimerization of thiyl radicals which can produce diphenyl disulfide.

A possible alternative to recombination of thiyl radicals is their interaction [50] with oxygen, which should eventually lead to sulfur dioxide formation:

$$
\mathrm{C}_{6} \mathrm{H}_{5} \mathrm{~S}^{\bullet}+\mathrm{O}_{2} \longrightarrow \mathrm{C}_{6} \mathrm{H}_{5} \mathrm{SO}_{2}^{\bullet} \underset{\mathrm{TiO}_{2}}{\stackrel{\mathrm{h} \nu}{\longrightarrow}} \mathrm{SO}_{2}+\text { other products. }
$$

Further oxidation of $\mathrm{SO}_{2}$ results in the formation of sulfate ions residing on the surface of $\mathrm{TiO}_{2}$.

Recombination of the thiyl radical and a radical generated from benzaldehyde can be considered as a possible route to phenyl thiobenzoat [51]:

$$
\mathrm{C}_{6} \mathrm{H}_{5} \mathrm{~S}^{\bullet}+\mathrm{C}_{6} \mathrm{H}_{5} \mathrm{C}^{\bullet} \mathrm{O} \longrightarrow \mathrm{C}_{6} \mathrm{H}_{5} \mathrm{SC}(\mathrm{O}) \mathrm{C}_{6} \mathrm{H}_{5}
$$

Also, an alternative process of decomposition of the thiyl radical cation leads to the formation of benzyl radicals [52]:

$$
\mathrm{C}_{6} \mathrm{H}_{5} \mathrm{~S}^{\bullet+} \mathrm{CH}_{2} \mathrm{C}_{6} \mathrm{H}_{5} \longrightarrow \mathrm{C}_{6} \mathrm{H}_{5} \mathrm{CH}_{2}^{\bullet}+\mathrm{C}_{6} \mathrm{H}_{5} \mathrm{~S}^{+} \text {. }
$$

Dimerization of two benzyl radicals causes the formation of dibenzyl, which was observed in the products in trace value,

$$
\mathrm{C}_{6} \mathrm{H}_{5} \mathrm{CH}_{2}^{\bullet}+\mathrm{C}_{6} \mathrm{H}_{5} \mathrm{CH}_{2}^{\bullet} \longrightarrow \mathrm{C}_{6} \mathrm{H}_{5} \mathrm{CH}_{2} \mathrm{CH}_{2} \mathrm{C}_{6} \mathrm{H}_{5} \text {. }
$$

Another possible path can be the direct reaction of sulfides with oxygen in the presence of UV photons [53]:

$$
\begin{aligned}
\mathrm{C}_{6} \mathrm{H}_{5} \mathrm{SCH}_{2} \mathrm{C}_{6} \mathrm{H}_{5} \underset{\mathrm{O}_{2}}{\stackrel{\mathrm{h} \nu}{\longrightarrow}} \mathrm{C}_{6} \mathrm{H}_{5} \mathrm{~S}(\mathrm{O}) \mathrm{CH}_{2} \mathrm{C}_{6} \mathrm{H}_{5} \\
\stackrel{\mathrm{h} \nu}{\underset{\mathrm{O}_{2}}{\longrightarrow}} \mathrm{C}_{6} \mathrm{H}_{5} \mathrm{~S}(\mathrm{O})_{2} \mathrm{CH}_{2} \mathrm{C}_{6} \mathrm{H}_{5} .
\end{aligned}
$$

Other processes may be operational during the photocatalytic oxidation of BPS, MPS, and $\mathrm{dPS}$ on the $\mathrm{TiO}_{2}$ surface and could yield diphenyl sulfoxide, thiophenol, methyl phenyl sulfoxide, phenyl propyl sulfide, n-buthyl phenyl sulfide, biphenyl, benzene, dipheny sulfone, and methyl phenyl sulfone. Some of these products were detected in trace amounts by GC-MS method. As said previously, the concentrations of all products were determined by GC method.

\section{CONCLUSION}

This study revealed that $\mathrm{TiO}_{2}$ photocatalytic one-electron oxidation reactions of MPS, BPS, and dPS adsorbed on the surface of $\mathrm{TiO}_{2}$ powder suspension in acetonitrile were observed. High varieties of products were detected by GC-MS analysis, ${ }^{1} \mathrm{H}$ NMR, and IR spectroscopy. The percentages of these products were determined by GC chromatography. These results suggest that these photocatalytic reactions were initiated by the formation of a surface bound cation radical generated by an interfacial electron transfer. The photogenerated hole localized at the surface of the irradiated semiconductor is trapped by an adsorbed organosulfur compound, which generated an adsorbed cation radical. In other words, the chemical bonding between substrates and the $\mathrm{TiO}_{2}$ surface play an important role in the oxidation mechanism as well as adsorption on the surface of $\mathrm{TiO}_{2}$ particles.

Results obtained in the presence of pure oxygen, atmospheric oxygen, and in the absence of oxygen showed that the process will proceed in the presence of pure oxygen much better than atmospheric oxygen or in the absence of oxygen. In fact, no detectable products were observed in the presence of atmospheric oxygen or argon flux. These results extensively verified that the rate of photooxidation processes and yield of products in the absence of $\mathrm{TiO}_{2}$ photocatalyst vigorously decreased. Thus in summary, this study provides an example of specific, controlled oxidative chemistry in organic substrates adsorbed on photoactivated $\mathrm{TiO}_{2}$ surface.

\section{ACKNOWLEDGMENT}

The authors wish to thank the University of Isfahan for financially supporting this work.

\section{REFERENCES}

[1] V. Iliev, A. Ileva, and L. Bilyarska, "Oxidation and photooxidation of sulfur-containing compounds in the presence of immobilized phthalocyanine complexes," Journal of Molecular Catalysis A: Chemical, vol. 126, no. 2-3, pp. 99-108, 1997.

[2] J. R. Salazar, Handbook of Petroleum Processes, Part 9, edited by R. A. Mayers, McGraw-Hill, New York, NY, USA, 1986.

[3] C. Wilson and D. M. Hirst, Progress in Reaction Kinetics, vol. 21, pp. 69-75, 1996.

[4] M. A. Fox and M. T. Dulay, "Heterogeneous photocatalysis," Chemical Reviews, vol. 93, no. 1, pp. 341-357, 1993.

[5] M. R. Hoffmann, S. T. Martin, W. Choi, and D. W. Bahnemann, "Environmental applications of semiconductor photocatalysis," Chemical Reviews, vol. 95, no. 1, pp. 69-96, 1995. 
[6] A. L. Linsebigler, G. Lu, and J. T. Yates Jr., "Photocatalysis on $\mathrm{TiO}_{2}$ surfaces: principles, mechanisms, and selected results," Chemical Reviews, vol. 95, no. 3, pp. 735-758, 1995.

[7] A. Mills and S. Le Hunte, "An overview of semiconductor photocatalysis," Journal of Photochemistry and Photobiology A: Chemistry, vol. 108, no. 1, pp. 1-35, 1997.

[8] A. Fujishima, T. N. Rao, and D. A. Tryk, "Titanium dioxide photocatalysis," Journal of Photochemistry and Photobiology C: Photochemistry Reviews, vol. 1, no. 1, pp. 1-21, 2000.

[9] A. Mills, R. H. Davies, and D. Worsley, "Water purification by semiconductor photocatalysis," Chemical Society Reviews, vol. 22, no. 6, pp. 417-425, 1993.

[10] P. V. Kamat, "Photochemistry on nonreactive and reactive (semiconductor) surfaces," Chemical Reviews, vol. 93, no. 1, pp. 267-300, 1993.

[11] P. V. Kamat, "Photophysical, photochemical and photocatalytic aspects of metal nanoparticles," Journal of Physical Chemistry B, vol. 106, no. 32, pp. 7729-7744, 2002.

[12] J. F. Kenneke, J. L. Ferry, and W. H. Glaze, "The titanium dioxide mediated photocatalytic degradation of chloroalkene," in Photocatalytic Purification and Treatment of Water and Air, D. F. Ollis and H. Al-Ekabi, Eds., pp. 179-191, Elsevier, London, Uk, 1993.

[13] A. Fujishima, K. Hashimoto, and T. Watanabe, $\mathrm{TiO}_{2}$ Photocatalysis: Fundamentals and Applications, BKC, Tokyo, Japan, 1999.

[14] J. Zhao and X. Yang, "Photocatalytic oxidation for indoor air purification: a literature review," Building and Environment, vol. 38, no. 5, pp. 645-654, 2003.

[15] S. Hager, R. Bauer, and G. Kudielka, "Photocatalytic oxidation of gaseous chlorinated organics over titanium dioxide," Chemosphere, vol. 41, no. 8, pp. 1219-1225, 2000.

[16] R. Nakamura, A. Imanishi, K. Murakoshi, and Y. Nakato, "In situ FTIR studies of pimary intermediates of photocatalytic reactions on nanocrystalline $\mathrm{TiO}_{2}$ films in contact with aqueous solutions," Journal of the American Chemical Society, vol. 125, no. 24, pp. 7443-7450, 2003.

[17] S. Sato, K. Ueda, Y. Kawasaki, and R. Nakamura, "In situ IR observation of surface species during the photocatalytic decomposition of acetic acid over $\mathrm{TiO}_{2}$ films," Journal of Physical Chemistry B, vol. 106, no. 35, pp. 9054-9058, 2002.

[18] R. B. Draper and M. A. Fox, "Titanium dioxide photosensitized reactions studied by diffuse reflectance flash photolysis in aqueous suspensions of $\mathrm{TiO}_{2}$ powder," Langmuir, vol. 6, no. 8, pp. 1396-1402, 1990.

[19] A. Y. Nosaka, T. Fujiwara, H. Yagi, H. Akutsu, and Y. Nosaka, "Photocatalytic reaction sites at the $\mathrm{TiO}_{2}$ surface as studied by solid-state 1H NMR spectroscopy," Langmuir, vol. 19, no. 6, pp. 1935-1937, 2003.

[20] M. A. Fox and M. T. Dulay, "Acceleration of secondary dark reactions of intermediates derived from adsorbed dyes on irradiated $\mathrm{TiO}_{2}$ powders," Journal of Photochemistry and Photobiology A: Chemistry, vol. 98, no. 1-2, pp. 91-101, 1996.

[21] D. P. Colombo Jr. and R. M. Bowman, "Does interfacial charge transfer compete with charge carrier recombination? A femtosecond diffuse reflectance investigation of $\mathrm{TiO}_{2}$ nanoparticles," Journal of Physical Chemistry, vol. 100, no. 47, pp. 1844518449, 1996.

[22] A. Furube, T. Asahi, H. Masuhara, H. Yamashita, and M. Anpo, "Direct observation of interfacial hole transfer from a photoexcited $\mathrm{TiO}_{2}$ particle to an adsorbed molecule SCN- by femtosecond diffuse reflectance spectroscopy," Research on Chemical Intermediates, vol. 27, no. 1-2, pp. 177-187, 2001.
[23] T. Tachikawa, S. Tojo, M. Fujitsuka, and T. Majima, "Oneelectron oxidation of aromatic sulfides adsorbed on the surface of $\mathrm{TiO}_{2}$ particles studied by time-resolved diffuse reflectance spectroscopy," Chemical Physics Letters, vol. 382, no. 5-6, pp. 618-625, 2003.

[24] C. D. Jaeger and A. J. Bard, "Spin trapping and electron spin resonance detection of radical intermediates in the photodecomposition of water at titanium dioxide particulate systems," Journal of Physical Chemistry, vol. 83, no. 24, pp. 3146-3146, 1979.

[25] R. F. Howe and M. Graetzel, "EPR study of hydrated anatase under UV irradiation," Journal of Physical Chemistry, vol. 91, no. 14, pp. 3906-3909, 1987.

[26] O. I. Micic, Y. Zhang, K. R. Cromack, A. D. Trifunac, and M. C. Thurnauer, "Trapped holes on titania colloids studied by electron paramagnetic resonance," Journal of Physical Chemistry, vol. 97, no. 28, pp. 7277-7283, 1993.

[27] J. Fan and J. T. Yates Jr., "Mechanism of photooxidation of trichloroethylene on $\mathrm{TiO}_{2}$ : detection of intermediates by infrared spectroscopy," Journal of the American Chemical Society, vol. 118, no. 19, pp. 4686-4692, 1996.

[28] D. Lawless, N. Serpone, and D. Meisel, "Role of hydroxyl radicals and trapped holes in photocatalysis. A pulse radiolysis study," Journal of Physical Chemistry, vol. 95, no. 13, pp. 51665170, 1991.

[29] M. W. Peterson, J. A. Turner, and A. J. Nozik, "Mechanistic studies of the photocatalytic behavior of titania: particles in a photoelectrochemical slurry cell and the relevance to photodetoxification reactions," Journal of Physical Chemistry, vol. 95, no. 1, pp. 221-225, 1991.

[30] C. Kormann, D. W. Bahnemann, and M. R. Hoffmann, "Photolysis of chloroform and other organic molecules in aqueous $\mathrm{TiO}_{2}$ suspensions," Environmental Science and Technology, vol. 25, no. 3, pp. 494-500, 1991.

[31] J. Cunningham and S. Srijarahai, "Isotope-effect evidence for hydroxyl radical involvement in alcohol photo-oxidation sensitized by $\mathrm{TiO}_{2}$ in aqueous suspension," Journal of Photochemistry and Photobiology A: Chemistry, vol. 43, no. 3, pp. 329335, 1988.

[32] M. A. Grela, M. E. J. Coronel, and A. J. Colussi, "Quantitative spin-trapping studies of weakly illuminated titanium dioxide sols. Implications for the mechanism of photocatalysis," Journal of Physical Chemistry, vol. 100, no. 42, pp. 16940-16946, 1996.

[33] P. F. Schwarz, N. J. Turro, S. H. Bossmann, A. M. Braun, A.-M. A. Abdel Wahab, and H. Dürr, "A new method to determine the generation of hydroxyl radicals in illuminated $\mathrm{TiO}_{2}$ suspensions," Journal of Physical Chemistry B, vol. 101, no. 36, pp. 7127-7134, 1997.

[34] M. H. Habibi and H. Vosooghian, "Photocatalytic degradation of some organic sulfides as environmental pollutants using titanium dioxide suspension," Journal of Photochemistry and Photobiology A: Chemistry, vol. 174, no. 1, pp. 45-52, 2005.

[35] T. Tachikawa, S. Tojo, M. Fujitsuka, and T. Majima, "Influences of adsorption on $\mathrm{TiO}_{2}$ photocatalytic one-electron oxidation of aromatic sulfides studied by time-resolved diffuse reflectance spectroscopy," Journal of Physical Chemistry B, vol. 108, no. 19, pp. 5859-5866, 2004.

[36] T. Tachikawa, S. Tojo, M. Fujitsuka, and T. Majima, "Photocatalytic one-electron oxidation of biphenyl derivatives strongly coupled with the $\mathrm{TiO}_{2}$ surface," Langmuir, vol. 20, no. 7, pp. 2753-2759, 2004. 
[37] T. Tachikawa, S. Tojo, M. Fujitsuka, and T. Majima, "Formation of the dimer radical cation of aromatic sulfide on the $\mathrm{TiO}_{2}$ surface during photocatalytic reactions," Langmuir, vol. 20, no. 11, pp. 4327-4329, 2004.

[38] R. B. Draper and M. A. Fox, "Titanium dioxide photooxidation of thiocyanate: $(\mathrm{SCN})_{2}^{:-}$studied by diffuse reflectance flash photolysis," Journal of Physical Chemistry, vol. 94, no. 11, pp. 4628-4634, 1990.

[39] R. B. Draper and M. A. Fox, "Titanium dioxide photosensitized reactions studied by diffuse reflectance flash photolysis in aqueous suspensions of $\mathrm{TiO}_{2}$ powder," Langmuir, vol. 6, no. 8, pp. 1396-1402, 1990.

[40] A. V. Vorontsov, E. V. Savinov, L. Davydov, and P. G. Smirniotis, "Photocatalytic destruction of gaseous diethyl sulfide over $\mathrm{TiO}_{2}$," Applied Catalysis B: Environmental, vol. 32, no. 1-2, pp. 11-24, 2001.

[41] A. V. Vorontsov, E. N. Savinov, C. Lion, and P. G. Smirniotis, " $\mathrm{TiO}_{2}$ reactivation in photocatalytic destruction of gaseous diethyl sulfide in a coil reactor," Applied Catalysis B: Environmental, vol. 44, no. 1, pp. 25-40, 2003.

[42] M. H. Habibi, S. Tangestaninejad, and B. Yadollahi, "Photocatalytic mineralisation of mercaptans as environmental pollutants in aquatic system using $\mathrm{TiO}_{2}$ suspension," Applied Catalysis B: Environmental, vol. 33, no. 1, pp. 57-63, 2001.

[43] M. H. Habibi, S. Tangestaninejad, and B. Yadollahi, "Detoxification of water containing para-methyl thiophenol with photocatalytic oxygenation on titanium dioxide," Journal of Industrial Pollution Control, vol. 24, pp. 80-89, 2000.

[44] M. H. Habibi, M. Khaledisardashti, and M. Montazerozohori, "Photocatalytic mineralisation of aniline derivatives in aquatic systems using semiconductor oxides," Annali di Chimica, vol. 94, no. 5-6, pp. 421-428, 2004.

[45] G. Pothenberger, J. Moser, M. Graetzel, N. Serpone, and D. K. Sharama, "Charge carrier trapping and recombination dynamics in small semiconductor particles," Journal of the American Chemical Society, vol. 107, no. 26, pp. 8054-8059, 1985.

[46] N. Serpone, D. Lawless, R. Khairutdinov, and E. Pelizzetti, "Subnanosecond relaxation dynamics in $\mathrm{TiO}_{2}$ colloidal sols (particle sizes $\mathrm{Rp}=1.0-13.4 \mathrm{~nm}$ ). Relevance to heterogeneous photocatalysis," Journal of Physical Chemistry, vol. 99, no. 45, pp. 16655-16661, 1995.

[47] D. W. Bahnemann, M. Hilgendorff, and R. Memming, "Charge carrier dynamics at $\mathrm{TiO}_{2}$ particles: reactivity of free and trapped holes," Journal of Physical Chemistry B, vol. 101, no. 21, pp. 4265-4275, 1997.

[48] D. P. Colombo Jr., K. A. Roussel, J. Saeh, D. S. Skinner, J. J. Cavaleri, and R. M. Bowman, "Femtosecond study of the intensity dependence of electron-hole dynamics in $\mathrm{TiO}_{2}$ nanoclusters," Chemical Physics Letters, vol. 232, no. 3, pp. 207-214, 1995.

[49] D. E. Skinner, D. P. Colombo Jr., J. J. Cavaleri, and R. M. Bowman, "Femtosecond investigation of electron trapping in semiconductor nanoclusters," Journal of Physical Chemistry, vol. 99, no. 20, pp. 7853-7856, 1995.

[50] J. E. Packer, "The radiation chemistry of thiol," in The Chemistry of the Thiol Group, Part 2, S. Patai, Ed., p. 501, John Wiley \& Sons, London, UK, 1974.

[51] M. R. Nimlos, E. J. Wolfrum, M. L. Brewer, J. A. Fennell, and G. Bintner, "Gas-phase heterogeneous photocatalytic oxidation of ethanol: pathways and kinetic modeling," Environmental Science and Technology, vol. 30, no. 10, pp. 3102-3110, 1996.

[52] R. S. Davidson and J. E. Pratt, "The titanium dioxide sensitised photo-oxidation of sulphides," Tetrahedron Letters, vol. 24, no. 52, pp. 5903-5906, 1983.
[53] E. L. Clenna, W. Zhou, and J. Chan, "Mechanistic organic chemistry in a microreactor. Zeolite-controlled photooxidations of organic sulfides," The Journal of Organic Chemistry, vol. 67, no. 26, pp. 9368-9378, 2002. 


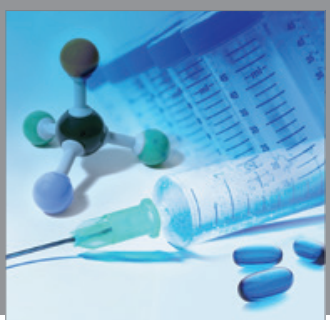

International Journal of

Medicinal Chemistry

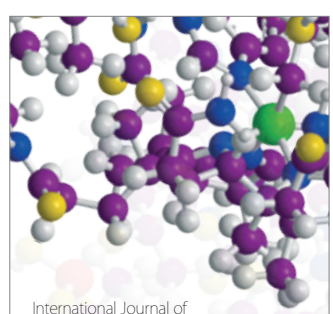

Carbohydrate Chemistry

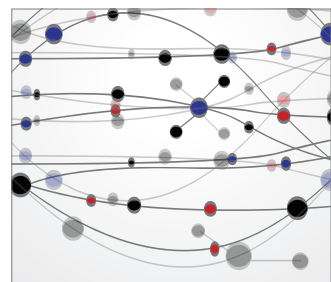

The Scientific World Journal
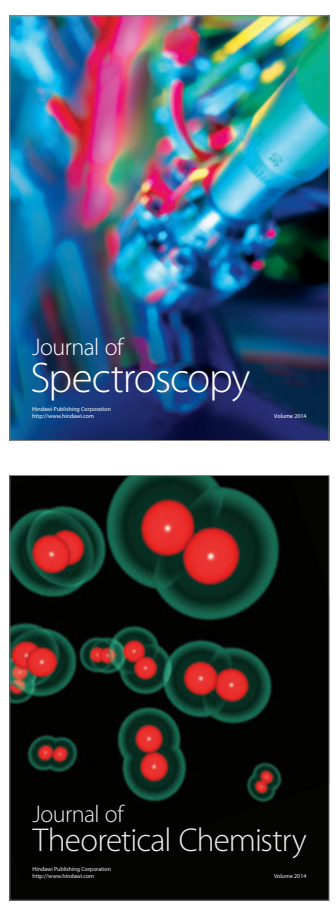
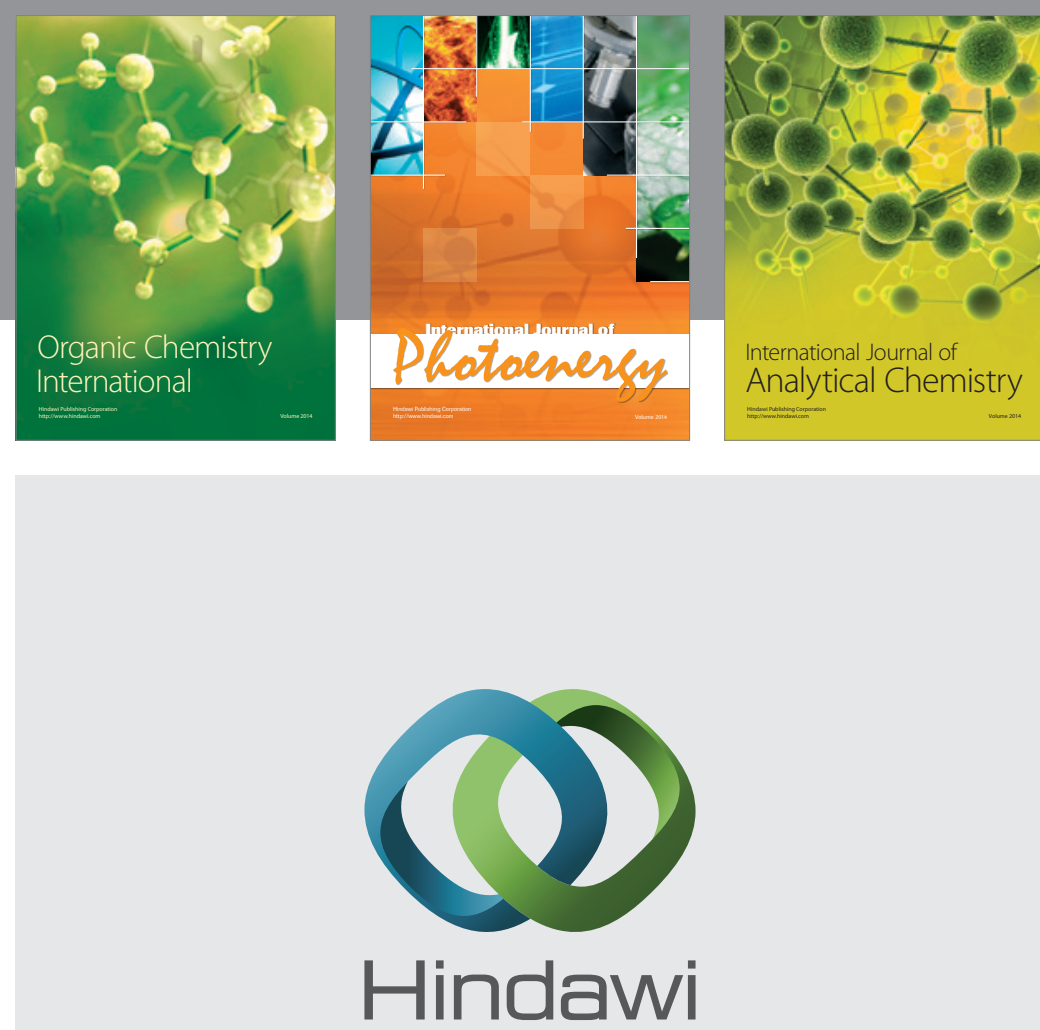

Submit your manuscripts at

http://www.hindawi.com
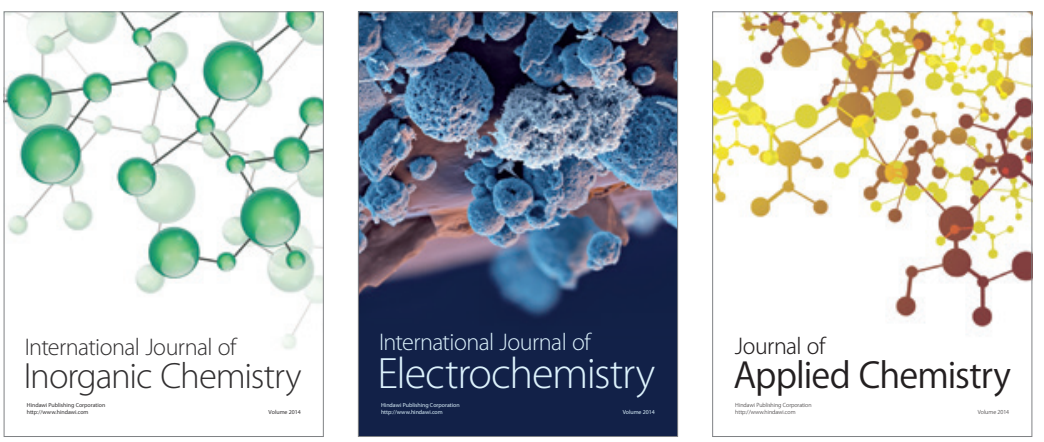

Journal of

Applied Chemistry
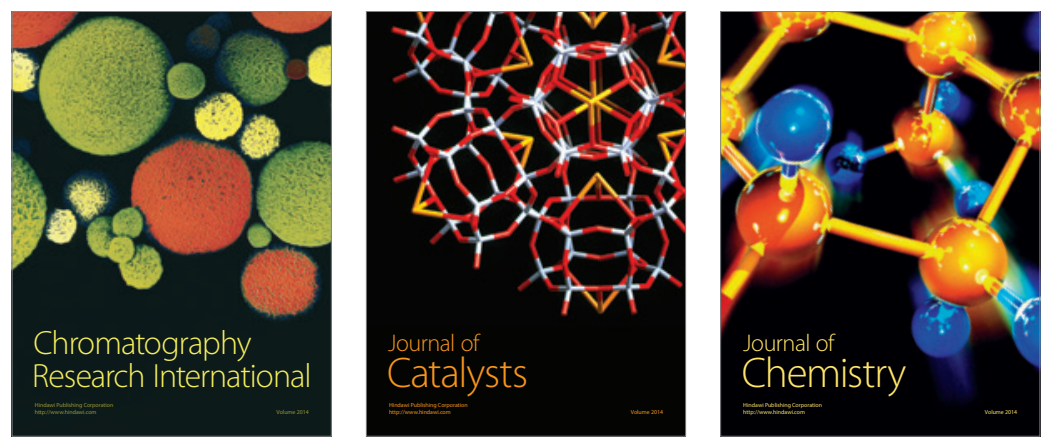
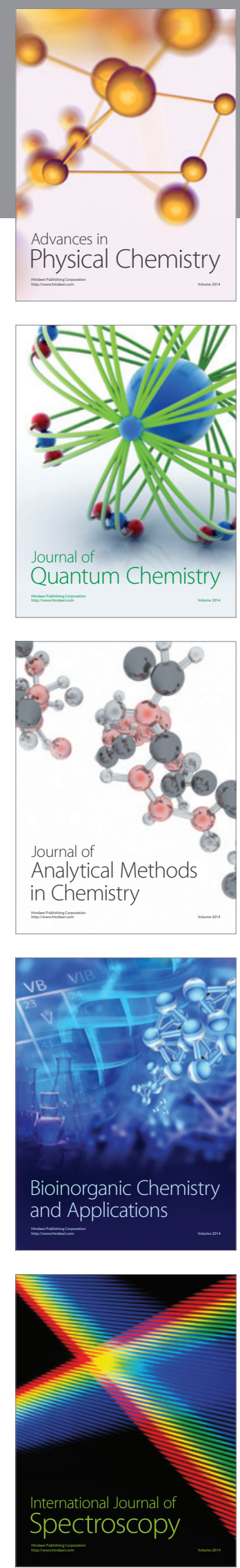